\title{
Role of accumbens BDNF and TrkB in cocaine-induced psychomotor sensitization, conditioned-place preference, and reinstatement in rats
}

\author{
Amine Bahi • Frederic Boyer • Vijay Chandrasekar • \\ Jean-Luc Dreyer
}

Published online: 30 July 2008

(C) Springer-Verlag 2008

\begin{abstract}
After publication of the paper, the authors noticed that one author's name has been omitted by mistake. The list of authors for this paper should include CHANDRASEKAR VIJAY, as third author.

The full list of authors should then read:

BAHI Amine, BOYER Frederic, CHANDRASEKAR VIJAY and DREYER Jean-Luc.

The full address of Mr. Vijay Chandrasekar is: Biochemistry, Department of Medicine, University of Fribourg, Rue du Musée 5, CH-1700 Fribourg, Switzerland, email: chandrasekar.vijay@unifr.ch
\end{abstract}

The authors are very sorry for this confusion.

The online version of the original article can be found at http://dx.doi. org/10.1007/s00213-008-1164-1.

\footnotetext{
F. Boyer $\cdot$ J.-L. Dreyer $(\bowtie)$

Division of Biochemistry, Department of Medicine,

University of Fribourg,

Rue du Musée 5,

CH-1700 Fribourg, Switzerland

e-mail: jean-luc.dreyer@unifr.ch

V. Chandrasekar

Biochemistry, Department of Medicine,

University of Fribourg,

Rue du Musée 5,

CH-1700 Fribourg, Switzerland

e-mail: chandrasekar.vijay@unifr.ch

Present address:

A. Bahi

Department of Psychiatry, Yale University School of Medicine,

301 Cedar Street,

New Haven, CT 06508, USA
} 